\title{
EFFECTS OF CAFFEINE ON THE MEMBRANE POTENTIALS AND CONTRACTILITY OF THE GUINEA PIG ATRIUM
}

\author{
Yosiko Кімото \\ Department of Physiology, Faculty of Medicine, Kyushu University, Fukuoka, Japan
}

\begin{abstract}
Summary 1. Effects of caffeine on the electrical and mechanical properties of the atrial muscle of guinea pig were investigated.

2. In normal Krebs solution, $3 \mathrm{~mm}$ caffeine caused a more than 5-fold potentiation of contraction. The potentiation, however, became smaller the higher the concentration, and $50 \mathrm{~mm}$ caffeine depressed the contraction somewhat in its later phase.
\end{abstract}

3. In $3 \mathrm{~mm}$ caffeine, the duration of action potential was prolonged up to $140 \%$ at a height of $80 \%$ of the spike, and in $50 \mathrm{~mm}$ caffeine, up to $230 \%$, whereas the membrane slope resistance was decreased. The rate of rise of the action potential appeared enhanced at the later phase.

4. In sodium-free Tris-maleate Krebs solution, even $3 \mathrm{~mm}$ caffeine evoked a contracture, and the contracture tension tended to increase with concentration of caffeine.

5. By soaking the muscle in low calcium Tris-maleate Krebs solution the amplitude of caffeine contracture decreased, first rapidly and then slowly with time, suggesting the contributions of surface membrane and internal calcium store towards contractile activation.

6. These results are interpreted as indicating that:

a) Caffeine acts on both the surface membrane and the sarcoplasmic reticulum in the myocardium.

b) Enhancing the inward calcium movement, caffeine augments the contraction both directly and indirectly through the sarcoplasmic reticulum.

c) In normal Krebs solution, the amount of the accumulated calcium is small but is increased by sodium depletion.

Effects of caffeine on the mechanical properties of skeletal muscle were reviewed by SANDOW (1965). In low concentrations, up to about 2-4 mM, its sole effect is potentiation of twitch contraction. This effect has been extensively in-

Received for publication December 6, 1971

木元良子 
vestigated by various authors. Using different methods, they found that caffeine caused a prolongation of the active state (RITCHIE, 1954) and an increase in the rate of tension development (SANDOW et al., 1965), but did not significantly alter the shape of the action potential (SANDOw et al., 1964). In higher concentrations, above $5 \mathrm{~mm}$, its predominant effect is to cause contracture.

Effects of caffeine on the mechanical and electrical properties of cardiac muscle have been investigated by several authors (SUZUKI, 1962; NAYLER, 1963; De GubarefF and Sleator, 1965; Clark and Olson, 1968), and it is reported that caffeine altered the duration of action potential. However, little is analysed about the relationship between the alterations of action potential and contractility induced by caffeine, and the site of action of caffeine is not elucidated.

The present experiments were carried out to investigate the effects of caffeine on the electrical and mechanical properties of the auricular muscle of guinea pig. The main purpose was to find the mode and site of action of caffeine.

\section{METHODS}

Auricular muscles freshly isolated from the left atrium of guinea pig hearts were used. Each muscle strip of about $0.5 \mathrm{~mm} \times 3 \mathrm{~mm} \times 5 \mathrm{~mm}$ was immersed in $30 \mathrm{ml}$ of Krebs solution. The chamber containing the solution was aerated with a mixture of $95 \% \mathrm{O}_{2}$ and $5 \% \mathrm{CO}_{2}$ and maintained at $37 \pm 0.5^{\circ} \mathrm{C}$. The composition of the solution was, in $\mathrm{mm} / \mathrm{liter}: \mathrm{NaCl}, 122.0 ; \mathrm{KCl} .4 .75 ; \mathrm{NaHCO}_{3}$, 15.5; $\mathrm{MgCl}_{2}, 0.83 ; \mathrm{KH}_{2} \mathrm{PO}_{4}, 1.19 ; \mathrm{CaCl}_{2}, 2.5 ;$ glucose, 11.5. The $\mathrm{pH}$ of the aerated solution was 7.4 .

The strip was pinned at one end and attached at the other end to the sensitive arm of a resistance wire strain gauge. A pair of grid electrodes $(10 \times 20 \mathrm{~mm}$ surface, $10 \mathrm{~mm}$ apart) were used for field stimulation. The basal driving frequency was 1 shock/sec. The stimuli consisted of rectangular pulses, $5 \mathrm{msec}$ in duration and less than twice the threshold voltage, which had been determined previously. The transmembrane potentials of single cells were recorded by inserting a flexibly mounted microelectrode into the muscle tissue. The tension of the strip was measured simultaneously with the recording of the action potentials.

Sodium-free solution was prepared by substituting sodium chloride and sodium bicarbonate in Tris-maleate.

To make solutions in which the concentrations of free ionized calcium are stabilized at low levels, $2 \mathrm{~mm}$ of EGTA (Ethylene glycol bis ( $\beta$-amino-ethyl ether)$\mathrm{N}, \mathrm{N}^{\prime}$-tetraacetic acid) was used as a chelating agent and $\mathrm{pH}$ of the solution was adjusted by Tris-maleate buffer $(\mathrm{pH}=7.1)$. The concentration of the free ionized calcium $\left[\mathrm{Ca}^{++}\right]$was calculated from the following equation presented by IMAI and TAKEDA (1967):

$$
P_{\mathrm{Ca}}=2 \mathrm{pH}-7.28+\log \left[\frac{(\mathrm{EGTA}) \text { added }}{\left(\mathrm{CaCl}_{2}\right) \text { added }}-1\right] \text {. }
$$


RESULTS

\section{Effects of caffeine on contractility}

As shown in Fig. $1 \mathrm{Aa}, \mathrm{b}$, and c, caffeine at a concentration of $3 \mathrm{~mm}$ in normal Krebs solution augmented the maximum twitch tension by an average of 5-fold ( \pm 1 S.D. of 6 determinations). $10 \mathrm{~mm}$ caffeine produced a similar effect (Fig. $1 \mathrm{Ba}, \mathrm{b}$, and $\mathrm{c}$ ), but the degree of potentiation of twitch contraction was slightly less than in the case of $3 \mathrm{~mm}$ caffeine. When the concentration of caffeine was raised to $50 \mathrm{mM}$, a potentiation occurred, but much less prominently than in the cases of $3 \mathrm{~mm}$ and $10 \mathrm{~mm}$ caffeine (Fig. $1 \mathrm{Ca}, \mathrm{b}$, and c). Moreover, the potentiation was followed by a depressed state and a slight contracture was often produced. Generally, the time course of the potentiation of twitch contraction under the influence of caffeine was very slow, in contrast with the skeletal muscle (LÜTTGAU and OETLIKER, 1968).

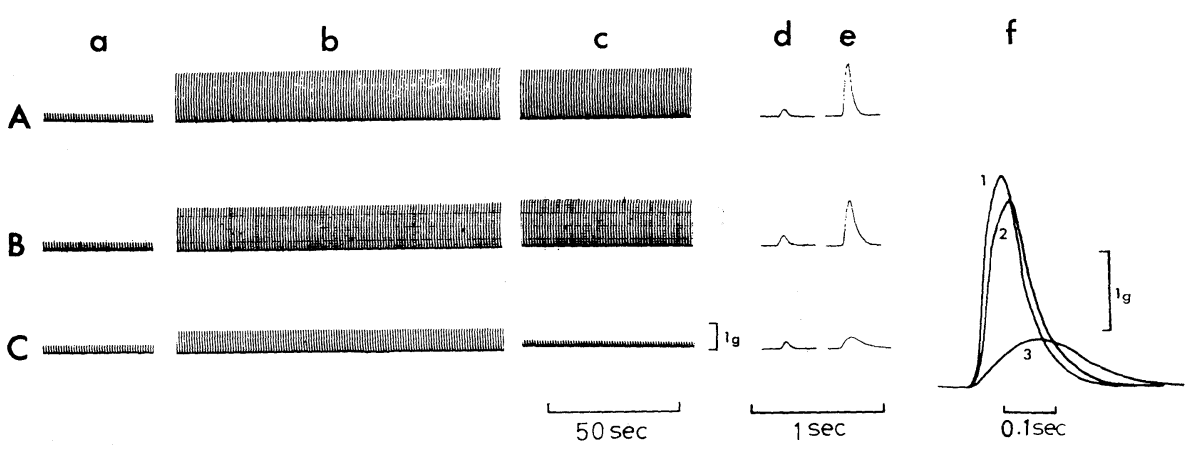

Fig. 1. Effects of $3 \mathrm{~mm}(\mathrm{~A}), 10 \mathrm{~mm}$ (B), and $50 \mathrm{~mm}$ (C) caffeine on the isometric contractile tension of the guinea pig atrium. Rate of stimulation: 1 shock/sec. a: Control records of isometric contractions. $\quad b$ : Records at 10-12 $\min (A), 16-17 \mathrm{~min}(\mathrm{~B})$, and 4-5 $\mathrm{min}$ (C) after the application of caffeine. c: Records at $15 \mathrm{~min}(\mathrm{~A}), 23 \mathrm{~min}(\mathrm{~B})$, and $20 \mathrm{~min}$ (C) after the application of caffeine. $\mathrm{d}$ : The control records of single isometric contraction. $\mathrm{e}$ : Records under the influence of caffeine. $\mathrm{f}$ : Superimposed tension tracings under the influence of $3 \mathrm{~mm}$ (1), $10 \mathrm{~mm}$ (2) and $50 \mathrm{~mm}$ (3) caffeine.

In calcium-free solution, the twitch contraction was markedly reduced and the potentiation of contraction induced by caffeine was very small, though the figures are not shown.

Figure 1, $d$ and e, shows the time courses of twitch contraction before and during the influence of $3 \mathrm{~mm}$ (A), $10 \mathrm{~mm}$ (B), and $50 \mathrm{~mm}$ (C) caffeine. As can be seen, 3 and $10 \mathrm{~mm}$ caffeine produced a prominent increase in rate of rise and duration of contraction. When the concentration of caffeine was raised to $50 \mathrm{~mm}$, a further increase in the duration of contraction was produced. However, the augmentation of peak tension as well as the rate of rise appeared rather depressed. 
Figure $1 \mathrm{f}$ indicates the superimposed tracings of the twitch tension in the presence of $3 \mathrm{~mm}(1), 10 \mathrm{~mm}(2)$ and $50 \mathrm{~mm}$ (3) caffeine.

Effects of caffeine on the electrical properties of the auricular cell

Resting potential. Resting potential was not significantly altered under the influence of $3 \mathrm{~mm}$ caffeine, but it decreased in the case of $50 \mathrm{~mm}$ (Table 1). The degree of decrease was not significantly different between the cases of presence or absence of contracture.
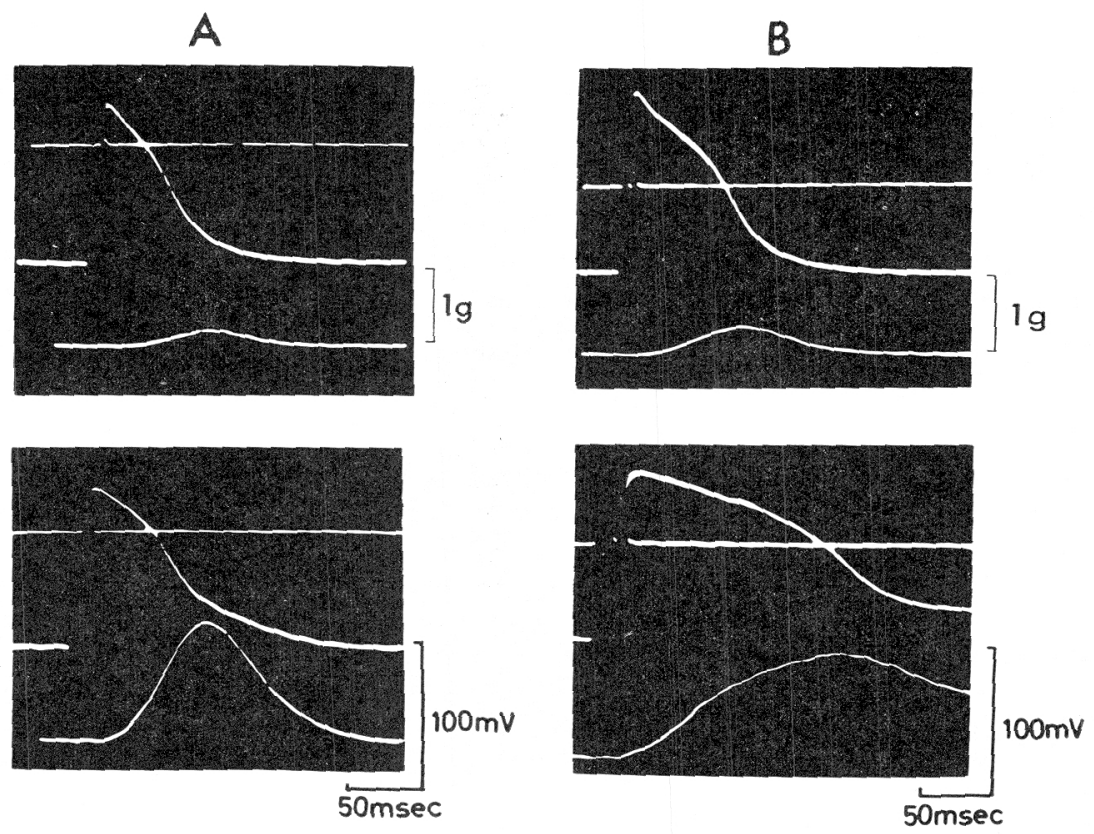

Fig. 2. Effects of caffeine on the transmembrane potentials and isometric contractile tenstions of the guinea pig atrium. (A) The upper figure: control. The lower one: $10 \mathrm{~min}$ after the application of $3 \mathrm{~mm}$ caffeine. (B) The upper figure: control. The lower one: $5 \mathrm{~min}$ after the application of $50 \mathrm{~mm}$ caffeine. In each record, the upper tracing is the electrical time derivative of depolarization, middle tracing the action potential, and lower tracing the contractile tension. Note a marked prolongation of the APD and an increase in height of the plateau under the influence of caffeine.

Action potentials. Figure 2 shows simultaneous recordings of the action potential and isometric contractile tension. Under the influence of $3 \mathrm{~mm}$ and 50 mM caffeine, height and duration of the plateau increased. This increase during the influence of caffeine was slow, and the alterations of the action potential duration (APD) and height of the plateau were qualitatively parallel.

In Table 1 it was shown that $3 \mathrm{~mm}$ caffeine prolonged the duration of the 
action potential up to a maximum of $140 \%$ when measured at a height of $80 \%$ from the resting level, whereas when measured at heights of $20 \%$ and $10 \%$ it was prolonged up to a maximum of $130 \%$. On the other hand, $50 \mathrm{~mm}$ caffeine prolonged the duration of action potential measured at heights of 80,20 , and $10 \%$ of the spike much more than $3 \mathrm{~mm}$ caffeine, with values of a maximum of 230 , 200 , and $200 \%$, respectively, when the drug potentiated the twitch. At the later stage, when $50 \mathrm{~mm}$ caffeine depressed the amplitude of twitch tension and induced a slight contracture, the action potential durations at heights of 80 and $20 \%$ of the spike were reduced to 160 and $140 \%$, respectively.

Table 1. Changes in the membrane potential produced by caffeine. The basal driving frequency was $1 / \mathrm{sec}$. Mean values (from 2-7 series of experiments) are given with the standard deviation.

\begin{tabular}{cccccccc}
\hline $\begin{array}{c}\text { Concentra- } \\
\text { tion of } \\
\text { caffeine } \\
(\mathrm{mm} / \text { liter })\end{array}$ & $\begin{array}{c}\mathrm{RP}^{\dagger} \\
(\mathrm{mV})\end{array}$ & $\begin{array}{c}\text { APt } \\
(\mathrm{mV})\end{array}$ & $\begin{array}{c}80 \% \\
\text { level }\end{array}$ & $\begin{array}{c}20 \% \\
\text { level }\end{array}$ & $\begin{array}{l}10 \% \\
\text { level }\end{array}$ & $\begin{array}{c}\text { Maximum } \\
\text { rate of rise } \\
(\mathrm{V} / \mathrm{sec})\end{array}$ & $\begin{array}{c}\text { Peak } \\
\text { tension } \\
(\%)\end{array}$ \\
\hline Control & $86 \pm 5$ & $108 \pm 18$ & $23 \pm 5$ & $57 \pm 2$ & $75 \pm 3$ & $79 \pm 3$ & 100 \\
3 & $85 \pm 9$ & $109 \pm 18$ & $33 \pm 3$ & $73 \pm 5$ & $96 \pm 8$ & $91 \pm 12$ & $548 \pm 97$ \\
Control & $80 \pm 6$ & $97 \pm 20$ & $19 \pm 2$ & $61 \pm 5$ & $77 \pm 5$ & $171 \pm 29$ & 100 \\
$50^{*}$ & $70 \pm 7$ & $100 \pm 9$ & $44 \pm 7$ & $98 \pm 32$ & $122 \pm 40$ & $110 \pm 26$ & $224 \pm 40$ \\
$50^{* *}$ & $67 \pm 9$ & $92 \pm 8$ & $30 \pm 8$ & $83 \pm 26$ & $130 \pm 45$ & $46 \pm 21$ & $48 \pm 8$ \\
\hline
\end{tabular}

* contracture absent, ** contracture present,

$\dagger$ resting potential, $\dagger$ action potential.

Membrane resistance. The membrane resistance changes before and during the influence of $3 \mathrm{~mm}$ caffeine were measured by the partition chamber method (KAMIYAMA and MATSUDA, 1966) with two pulse generators, one for ordinary stimulation and the other for repetitive small and short square pulses of anodal current. The results obtained are illustrated in Fig. 3. In the experiment illustrated by Fig. 3B, a few action potentials were superimposed by synchronizing the time base with the upstroke of the spike. The upper edge of the single (Fig. 3A) or the superimposed traces (Fig. 3B) corresponds to an action potential in the absence of applied current, while the lower edge represents action potential displaced by anodal current. The amplitude of the voltage changes is proportional to the square root of membrane resistance. Three $\mathrm{mm}$ caffeine decreased the membrane slope resistance measured at 10 and $20 \mathrm{msec}$ after the upstroke of the spike up to 72 and $84 \%$, respectively, when the corresponding normal values are expressed as $100 \%$. Similarly, $50 \mathrm{~mm}$ caffeine decreased the membrane slope resistance measured at 3,10 , and $20 \mathrm{msec}$ after the upstroke of the spike, with values of 80,82 , and $69 \%$ respectively.

Rising phase of the action potential. Figure $4 \mathrm{a}$ and $\mathrm{b}$, shows the records of the rising phase of the atrial action potential of the guinea pig before and during the influence of $3 \mathrm{~mm}$ and $50 \mathrm{~mm}$ caffeine. In this case, the potentiation of twitch 

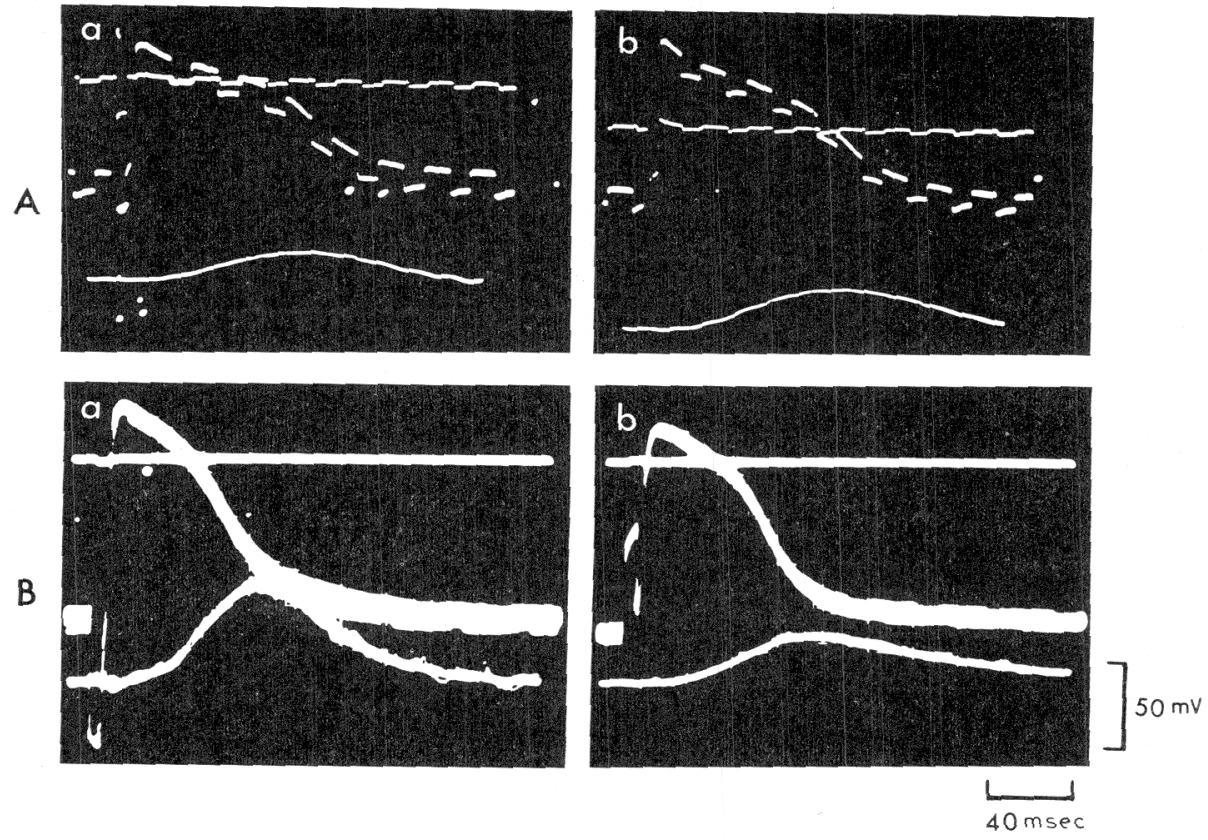

Fig. 3. Changes in membrane resistance during action potential in auricular fiber. (A) a: control. b: 15 min after addition of $3 \mathrm{~mm}$ caffeine. (B) a: control. b: 20 min after addition of $50 \mathrm{~mm}$ caffeine. Records of several sweeps are superimposed. Anodal pulses of $10 \mathrm{msec}$ duration at $30 \mathrm{cps}$ (A) and $20 \mathrm{cps}$ (B) were applied. In each record, the upper tracing is the monitor of current, middle tracing the action potential, and lower tracing the contractile tension.

contraction was four- and two-fold at $3 \mathrm{~mm}$ and $50 \mathrm{~mm}$ caffeine, respectively. As is illustrated in the figure, $3 \mathrm{~mm}$ caffeine accelerated the fast upstroke, but $50 \mathrm{~mm}$ caffeine decreased it ( $c f$. Table 1). On the other hand, the rate of slower rise of the action potential was increased by both $3 \mathrm{~mm}$ and $50 \mathrm{~mm}$ caffeine. In Fig. $4 \mathrm{c}$, in which the rate of depolarization, $d V / d t$, has been plotted against the time which elapsed after the point of the fastest upstroke, it is clear that throughout this later phase the potential rises faster in the presence of caffeine. Taking the ratio of the ordinates, in $3 \mathrm{~mm}$ or $50 \mathrm{~mm}$ caffeine and in the control, the value was 1.4 in the former and 1.5 in the latter for 1 and $0.5 \mathrm{msec}$, respectively. In the same figure, the rate of repolarization was plotted as the negative value of $d V / d t$ from the records of whole action potential, which correspond to the records of rising phase of the action potential, although the figures are not shown. The figure indicates that the rate of repolarization at 10 or $20 \mathrm{msec}$ from the upstroke of the spike was depressed markedly in the presence of caffeine, especially in the case of $50 \mathrm{~mm}$ caffeine. 

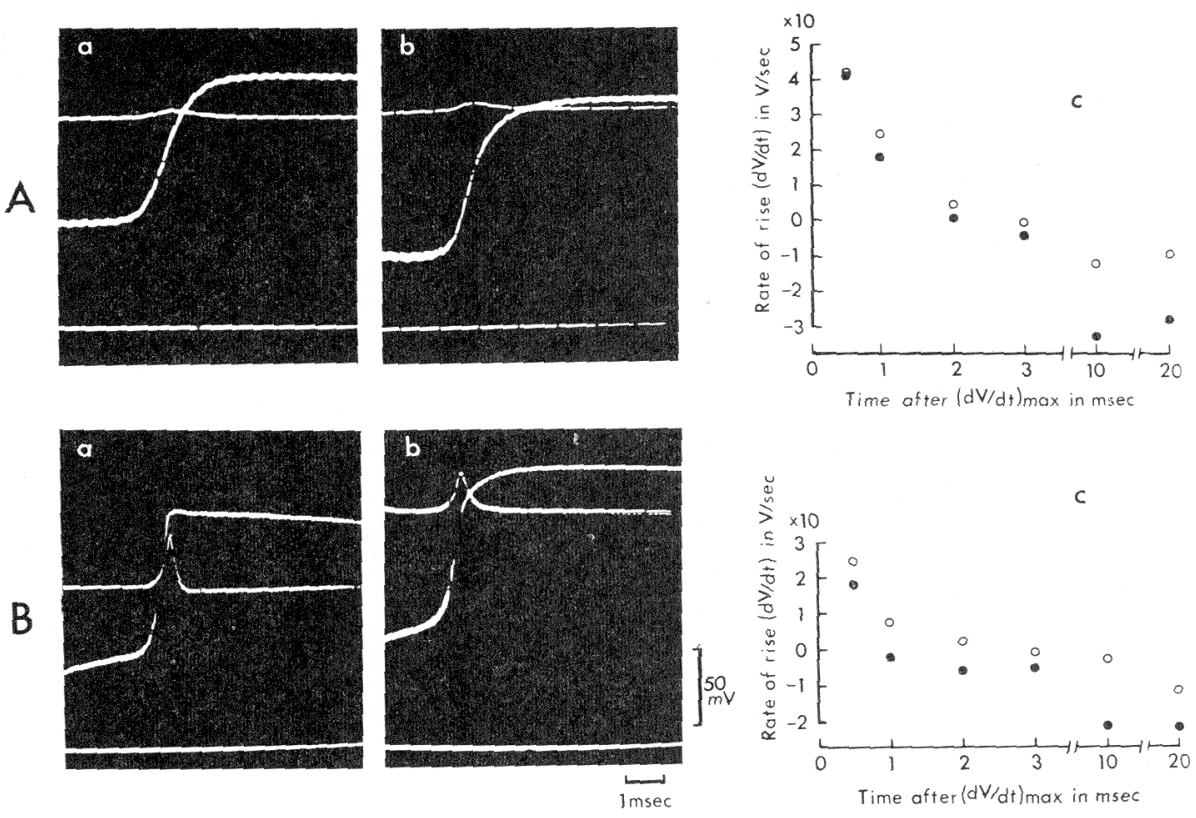

Fig. 4. Effects of $3 \mathrm{~mm}(\mathrm{~A})$ and $50 \mathrm{~mm}$ (B) caffeine on the rising phase of the action potential. (a) The control records. (b) Those under the influence of caffeine. (c) The values $(d V / d t)$ of the control (filled circles) and in the presence of caffeine (open circles) plotted against the time after the point of $(d V / d t) \max$. In each record, the upper tracing is the electrical time derivative of depolarization, middle tracing the action potential, and lower tracing the tension.

\section{Relationship between electrical and mechanical properties in the presence of caffeine}

In order to see the relationship between the electrical and mechanical changes, the per cent increase in duration of the action potential (APD) measured at a height of $80 \%$ of the spike and the per cent augmentation of the peak tension induced by $3 \mathrm{~mm}$ (A) and $50 \mathrm{~mm}$ (B) caffeine are plotted in Fig. 5, where the normal values are expressed as $100 \%$. As seen in the figure, in the presence of $3 \mathrm{~mm}$ caffeine, the peak tension increased markedly from $100 \%$ to a maximum of $760 \%$, while APD was prolonged less markedly, to a maximum of $140 \%$. With $50 \mathrm{~mm}$ caffeine, the peak tension reached a maximum of $300 \%$ and APD a maximum of $190 \%$. However, during the depressed state of twitch contraction under the influence of $50 \mathrm{~mm}$ caffeine, the contraction was decreased even when the action potential was prolonged (Fig. 5C).

Figure 6 shows the relationship between the time to peak tension and APD. The time to peak tension was plotted as a measure of the duration of contraction since the changes of the time to peak tension and the duration of contraction induced by caffeine were almost parallel. As can be seen, plots of the time to peak 
tension against action potential duration appeared linear with $3 \mathrm{~mm}, 10 \mathrm{~mm}$, and $50 \mathrm{~mm}$ caffeine, and indicate that the APD and time to peak tension increase together as the concentration of caffeine is raised.
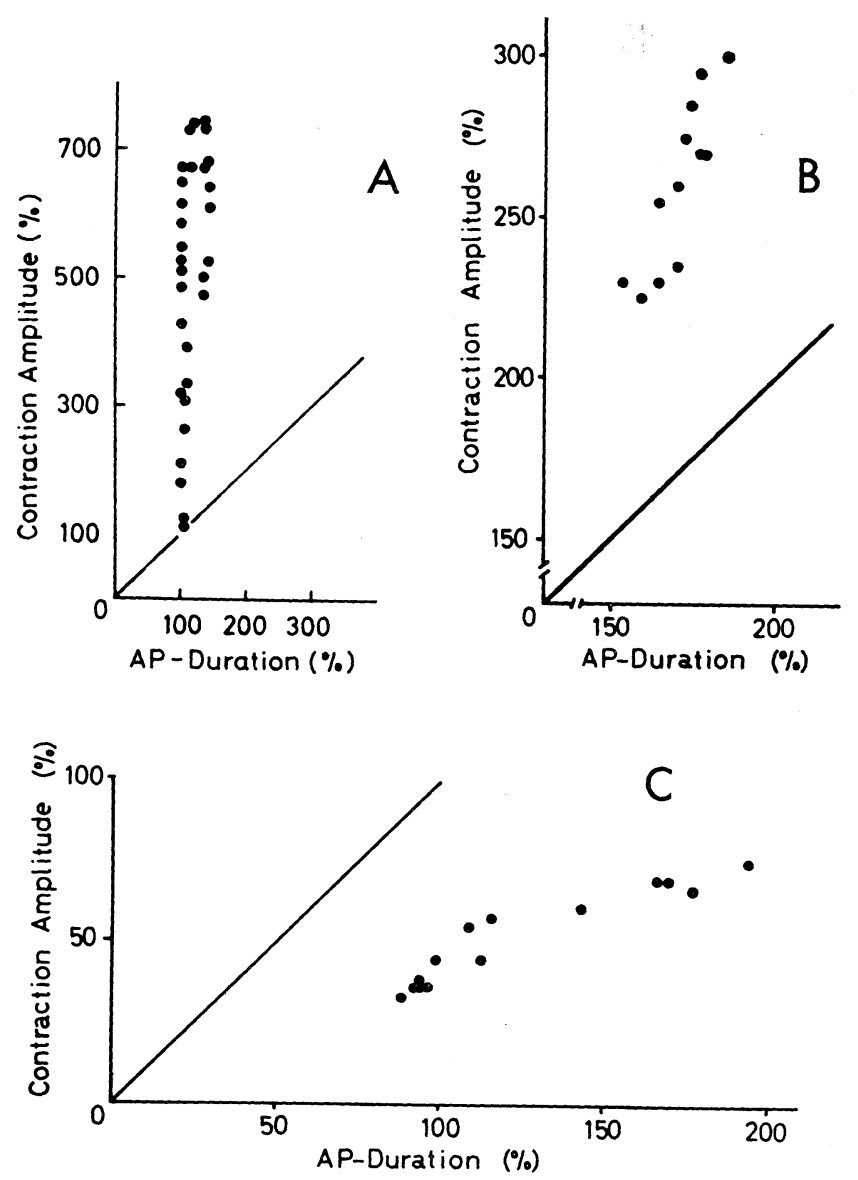

Fig. 5. Relationship between contraction amplitude and action potential duration at a height of $80 \%$ of the spike in the presence of $3 \mathrm{~mm}(\mathrm{~A})$ and $50 \mathrm{~mm}$ caffeine (B: the potentiating stage, and $\mathrm{C}$ : depressive stage). Continuous lines indicate the increase in equal percentages of the contraction and action potential duration. Plots in A were measured starting immediately after the application of caffeine until several minutes after the maximum potentiation of twitch contraction, plots in B starting about 5 min after the application of caffeine until the maximum potentiation, and plots in $\mathrm{C}$ for several minutes after the maximum potentiation.

\section{Characteristics of caffeine contracture in sodium-free solution}

General behavior of caffeine contracture. It was reported that in the frog ventricle caffeine contracture was easily induced in sucrose-Ringer solution lacking 


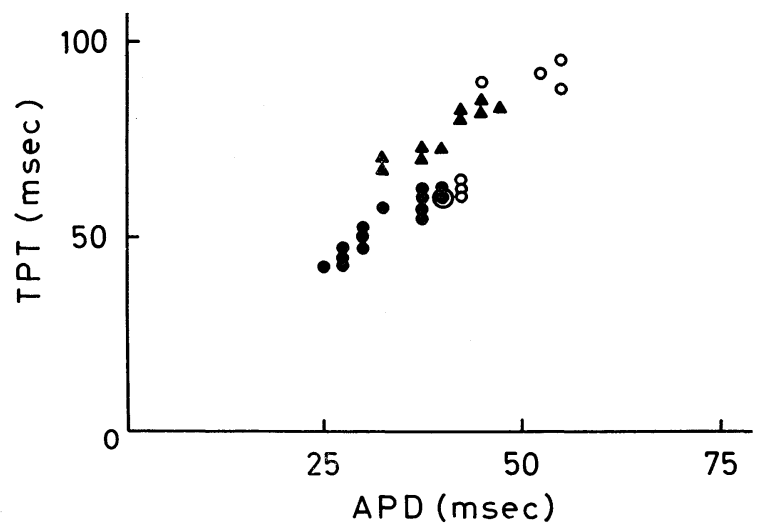

Fig. 6. Relationship between the time to peak tension (TPT) and action potential duration (APD) at a height of $80 \%$ of the spike in the presence of $3 \mathrm{~mm}$ (filled circles), $10 \mathrm{~mm}$ (filled triangles), and $50 \mathrm{~mm}$ caffeine (open circles).

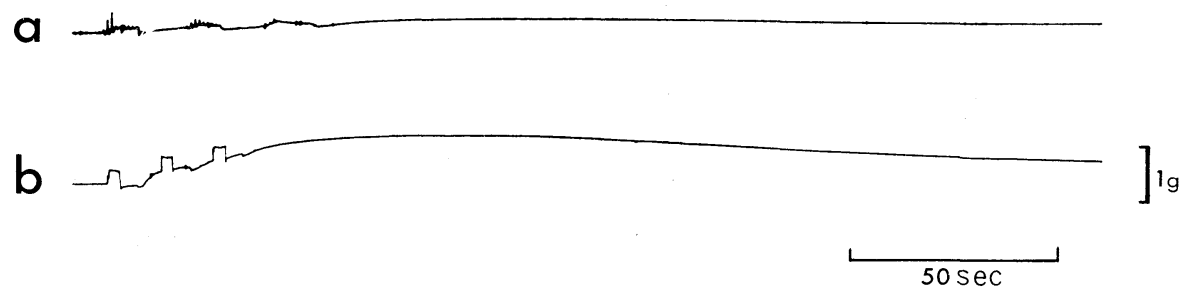

Fig. 7. Time course of the caffeine-induced contracture of guinea pig atrial fibers after soaking the muscle for 20-30 min in Tris-maleate Krebs solution. (a) $3 \mathrm{~mm}$ caffeine. (b) $50 \mathrm{~mm}$ caffeine. The bathing solution was exchanged three times with caffeine-containing Tris-maleate Krebs solution, in order to expect the complete replacement. Mechanical artifacts were marked in such a procedure.

sodium ions (SuzUKI, 1962). Further examination was carried out in sodiumfree Tris-maleate Krebs solution in order to investigate the characteristics of the caffeine-induced contracture of the guinea pig atrium.

Figure 7 shows the recordings of tension elicited in auricular muscle fibers bathed in sodium-free (Tris) Krebs solution to which $3 \mathrm{~mm}$ (a) or $50 \mathrm{~mm}$ (b) caffeine had been added. Caffeine was applied 20-30 min after the substitution of sodium chloride and sodium bicarbonate to Tris-maleate, since transient contracture occurred in the sodium-free solution. As seen in the figure, even $3 \mathrm{~mm}$ caffeine, as well as $50 \mathrm{~mm}$ caffeine, evoked a distinct contracture in sodium-free solution. The rate of rise and the peak contracture tension, however, increased markedly as the caffeine concentration was increased.

Role of external calcium. In order to find the source of calcium which contributes to the caffeine contracture in sodium-free solution, the behavior of caf- 
feine contracture was investigated in sodium-free and calcium-depleted solution. Figure 8 shows an example of the effects of the depletion of calcium on caffeine contracture. The solution in which the muscle was soaked contained $6.1 \times 10^{-7} \mathrm{M}$ free ionized calcium and was adjusted to the ratio of calcium and EGTA added to Tris-maleate Krebs solution. In this experiment, each application of $50 \mathrm{~mm}$ caffeine lasted about $5 \mathrm{~min}$, with $5 \mathrm{~min}$ (from A to B), $10 \mathrm{~min}$ (from B to C), and 15 min (from $C$ to $D$ ) intervals between applications. Contracture tension induced by the second application (B) of caffeine was reduced markedly. In the right hand figure, the peak tension evoked by $50 \mathrm{~mm}$ caffeine was plotted against the soaking time. As can be seen, caffeine contractures declined rapidly during the first $5 \mathrm{~min}$, then slowly. After $5 \mathrm{~min}$ of soaking in $6.1 \times 10^{-7} \mathrm{M} \mathrm{Ca}^{++}$, the contractile response to $50 \mathrm{~mm}$ caffeine decreased to about $30 \%$ of the initial value.
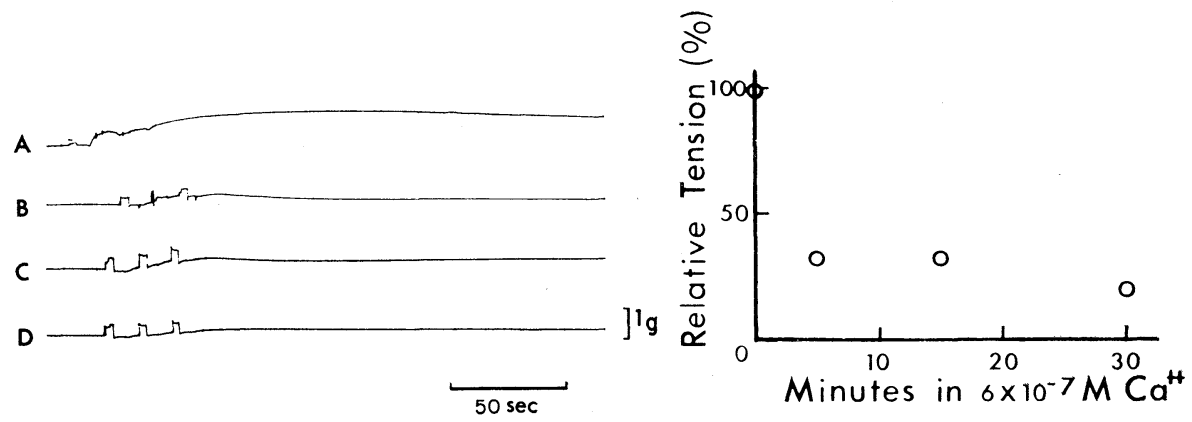

Fig. 8. Effect of low $\left(6.1 \times 10^{-7} \mathrm{M}\right)$ calcium solution on caffeine contracture. The muscle was equilibrated for about $30 \mathrm{~min}$ in a calcium-depleted Tris-maleate Krebs solution. The first addition of $50 \mathrm{~mm}$ caffeine (A) resulted in a large and slowly declining tension. Subsequent challenges with caffeine, after $5 \mathrm{~min}(\mathrm{~B}), 15 \mathrm{~min}$ (C), and $30 \mathrm{~min}$ (D) from (A), resulted in gradually smaller and briefer tensions. The right-hand figure shows a plot of the peak tensions evoked by $50 \mathrm{~mm}$ caffeine against the time after the muscle was soaked in low calcium Tris-maleate solution.

Minimum concentration of calcium ion required to induce the tension development by caffeine. Effects of caffeine ( $3 \mathrm{~mm}$ and $50 \mathrm{~mm}$ ) on the mechanical activities at various concentrations of calcium ion were investigated in sodium-free Krebs solution. Caffeine was added $30 \mathrm{~min}$ after the immersion of the calcium-deficient solution.

Table 2 shows the presence or absence of caffeine contracture at various concentrations of calcium ion $\left(\geqq 2.4 \times 10^{-6}-6.4 \times 10^{-9} \mathrm{M}\right)$ in Tris-maleate Krebs solution. Three $\mathrm{mm}$ caffeine did not produce tension development when the concentration of calcium ion was $1.9 \times 10^{-7} \mathrm{M}$, and the minimum concentration required to produce tension development by $3 \mathrm{~mm}$ caffeine was $2.4 \times 10^{-6} \mathrm{M} \mathrm{Ca}^{++}$. With $50 \mathrm{~mm}$ caffeine, the minimum concentration of calcium ion was $1.9 \times 10^{-7} \mathrm{M}$. 
Table 2. Dependence of the contracture on the external $\mathrm{Ca}^{++}$concentration which was adjusted with calcium-EGTA buffers

(pH about 7.1 ; temp. about $37^{\circ} \mathrm{C}$ ).

\begin{tabular}{|c|c|c|c|c|}
\hline \multicolumn{2}{|c|}{ Composition of the EGTA buffer } & \multirow{3}{*}{$\begin{array}{l}\text { Total number of } \\
\text { strips tested }\end{array}$} & \multirow{2}{*}{\multicolumn{2}{|c|}{$\begin{array}{c}\text { Number of strips undergoing } \\
\text { caffeine contracture }\end{array}$}} \\
\hline \multirow{2}{*}{$\frac{[\mathrm{Ca}] \text { added }}{[\mathrm{EGTA}] \text { added }}$} & \multirow{2}{*}{$\begin{array}{l}\text { Molar concen- } \\
\text { tration of } \mathrm{Ca}^{++}\end{array}$} & & & \\
\hline & & & $3 \mathrm{mM}$ & $50 \mathrm{~mm}$ \\
\hline$\geqq 0.95$ & $\geqq 2.4 \times 10^{-6}$ & 3 & 3 & 3 \\
\hline 0.61 & $1.9 \times 10^{-7}$ & 1 & 0 & 1 \\
\hline 0.34 & $6.2 \times 10^{-8}$ & 2 & 0 & 0 \\
\hline 0.05 & $6.4 \times 10^{-9}$ & 1 & 0 & 0 \\
\hline
\end{tabular}

\section{DISCUSSION}

In skeletal muscle, caffeine at a concentration of 1-4 mM produces a marked augmentation of twitch contraction without altering significantly the action potential (SANDOw et al., 1964; SANDOw, 1965). Our results on the auricular muscle, however, indicated that caffeine at comparable concentrations increased the duration and height of action potential considerably and decreased the membrane slope resistance. These results are in agreement with those on the guinea pig atrium (De GubarefF and Sleator, 1965) and on the kitten papillary muscle (CLARK and OlSON, 1968). In our results, these effects of caffeine on the action potential were found to be closely associated with the potentiation of the twitch contraction.

The increase in height and duration of the action potential, when considered with the decrease of membrane slope resistance, strongly suggests an enhancement of some inward movement of positive charges or outward movement of negative charges. Recent voltage clamp studies (Rougier et al., 1968, 1969; MASCHER and PEPER, 1969) have revealed that a slow channel allowing the penetration of both sodium and calcium ions exists in cardiac cells and this current is related to the positive plateau level of the myocardial action potential. Thus, as the positive charges, sodium and/or calcium ions could be considered. As for the negative charges, on the other hand, chloride ions would be sole candidate. The plateau potential in our case, however, appeared much higher than chloride equilibrium potential (-111 mV in rabbit atrium, De MeLlo, 1961; $-80 \mathrm{mV}$ in sheep Purkinje fibers, DuDEl et al., 1967), and since it was elevated due to caffeine, the possibility of increase of the chloride outward movement is hardly conceivable and could be neglected, although the exact chloride equilibrium potential in the guinea pig atrium is not known.

NAYLER (1963) found an increase of calcium influx when caffeine was applied in the cardiac muscle of toad, and recent voltage clamp experiments on dog ventricular muscle have shown that calcium current contributes to the activation 
of twitch contraction (REuTER and BeELer, 1969; BEeler and REUTER, 1970). In the guinea pig ventricle also, the calcium current was found to be responsible for the rate of rise and amplitude of twitch contraction (OCHI and TRAUTWEIN, 1971). Thus, the prolongation and augmentation of action potential, as well as twitch contraction observed under the influence of caffeine, could be considered mainly due to an increase of the calcium inward current. Though the estimation should be proved directly, the finding that caffeine actually increased the rate of rise in the late rising phase of the action potential supports this view.

In the sarcoplasmic reticulum isolated from frog skeletal muscle, it is well known that release of calcium ions is larger the higher the concentration of caffeine (WEBER and Herz, 1968). In the crayfish muscle fibers, it has been found that the rate of rise and peak tension increase markedly as the caffeine concentration is increased (ChIARANDini et al., 1970). They investigated the effect of caffeine in the range of concentrations between 1 and $80 \mathrm{~mm}$. In the present experiments on the guinea pig atrium, however, the potentiation of twitch contraction was smaller the larger the concentration of caffeine over $3 \mathrm{~mm}$. This could not be explained simply by the action of caffeine on the surface membrane.

Woon and his co-workers (1969) proposed a hypothesis that the cardiac action potential has a dual effect: (1) to fill calcium stores; and (2) to release the calcium ions from the stores. The release was thought to contribute also to contraction and presumably to be larger when more calcium was accumulated. Thus, when this hypothesis is applied to our case, the stores can be sufficiently filled with more calcium ions which result from the increased calcium current by caffeine unless the calcium uptake of the stores is inhibited. On the isolated reticulum from the frog skeletal muscle, however, TANIGUCHI and NAGAI (1970) reported that more than $10 \mathrm{~mm}$ caffeine does inhibit the calcium uptake. If the mechanism in the guinea pig auricle is similar, $3 \mathrm{~mm}$ caffeine does not inhibit the filling of the stores, whereas $50 \mathrm{~mm}$ caffeine does. Hence, the present results, that the potentiation of twitch contraction was larger the smaller the concentration of caffeine, can be explained by the amount of stored calcium which may be affected by caffeine.

In the present experiments it was found that caffeine, $50 \mathrm{~mm}$ in concentration, evoked only a slight contracture in the auricular muscle, while it is known that 5-10 mM caffeine produces a contracture which reaches the height of maximum potassium contracture in skeletal muscle (LUDIN et al., 1966). In sodium-free solution, however, a contracture of the auricular muscle was produced with $3 \mathrm{~mm}$ caffeine and contracture tension became larger as the concentration was increased. The latter results are compatible with those of the frog skeletal muscle (LÜTTGAU and Oetliker, 1968) and of the crayfish muscle (ChIARANDini et al., 1970). Under sodium-free conditions, a large cellular uptake of calcium does occur in myocardium (REUTER and SEITZ, 1968; LANGER, 1968) and an increasing number of binding sites are occupied. Thus, it is presumed in the present case that the 
amount of stored calcium is greater in the sodium-free solution and caffeine acts on the store in the atrium to produce contracture, as in the case of the skeletal muscle. This estimation may be supported by the facts that under normal conditions the calcium storage capacity is considerably less in myocardium than in skeletal muscle (FANBURG et al., 1964; HASSELBACH, 1964).

The soaking experiment showed that after $5 \mathrm{~min}$ of soaking the contractile response to $50 \mathrm{~mm}$ caffeine decreased rapidly. During this time the calcium in the extracellular fluid is thought to have been largely removed by soaking in the low $\mathrm{Ca}^{++}$solution (WINEGRAD and SHANES, 1962), since the half-time of the rapidly exchangeable component of the calcium of the guinea pig atrium is $4.5 \pm 0.2 \mathrm{~min}$. This may explain the rapid decrease of the contractile response to $50 \mathrm{~mm}$ caffeine in the present experiments, suggesting at least contribution of the surface membrane towards contractile activation. Under these conditions, however, calcium in the deep sites, probably in the sarcoplasmic reticulum, remains and is probably involved in the response in $50 \mathrm{~mm}$ caffeine, because the half-time of the slow component of the calcium washout curve is 86 (or 168) min in guinea pig atria (WINEGRAD and SHANES, 1962). Thus it is probable that caffeine acts on the sarcolemma as well as the sarcoplasmic reticulum in the myocardium.

In conclusion, from the effects of caffeine in the various ionic environment it is proposed that the effects on the cardiac muscle are fundamentally the same as those on the skeletal muscle. However, the modification of calcium current through the surface membrane affects the contractility both directly and indirectly via the sarcoplasmic reticulum, thus causing the responses different from those of the skeletal muscle.

The author wishes to express heartfelt gratitude to Professor M. Goto for his guidance and revision of this paper.

This investigation was presented at the 46th General Meeting of the Physiological Society of Japan, 1969.

\section{REFERENCES}

BeELER, G. W., Jr. and ReUter, H. (1970) Membrane calcium current in ventricular myocardial fibers. J. Physiol., 207: 191-209.

Chiarandini, D. J., Reuben, J. P., Brandt, P. W. and Grundfest, H. (1970) Effects of caffeine on crayfish muscle fibers I. Activation of contraction and induction of Ca spike electrogenesis. J. Gen. Physiol., 55: 640-664.

Clark, A. and Olson, C. (1968) Effects of caffeine on action potentials on mammalian ventricular cells. Fed. Proc., 27: 304.

De Gubareff, T. and Sleator, W. (1965) Effects of caffeine on mammalian atrial muscle and its interaction with adenosine and calcium. J. Pharmacol. Exp. Therap., 148: 202-214.

De Mello, W. C. (1961) Some aspects of interrelationship between ions and electrical activity in the specialized tissues of the heart. In The Specialized Tissues of the Heart, ed. by PAES De Carvalho, A., De Mello, W. C. and Hoffman, B. F. Elsevier, Amsterdam, 95-107. Dudel, J., Peper, K., RÜder, R. and Trautwein, W. (1967) The dynamic chloride component 
of membrane current in Purkinje fibers. Pflügers Arch., 295: 197-212.

FAnburg, B., Finkel, R. M. and Martonosi, A. (1964) Mechanism of relaxation of cardiac muscle. J. Biol. Chem., 239: 2298-2306.

Hasselbach, W. (1964) Relaxation and the sarcotubular calcium pump. Fed. Proc., 231: 909-912.

IMAI, S. and TAKEDA, K. (1967) Action of calcium and certain multivalent cations on potassium contracture of guinea-pig's taenia coli. J. Physiol., 190: 155-169.

Kamiyama, A. and Matsuda, K. (1966) Electrophysiological properties of the canine ventricular fiber. Jap. J. Physiol., 16: 407-420.

LANGER, G. A. (1968) Ion fluxes in cardiac excitation and contraction and their relaxation to myocardial contractility. Physiol. Rev., 48: 708-757.

Ludin, H. P., LütTgau, H. C. and Oetliker, H. (1966) The effect of caffeine on the initiation of contraction in isolated muscle fibres of the frog. J. Physiol., 186: 101-102 p.

Lüttgau, H. C. and Oetliker, H. (1968) The action of caffeine on the activation of the contractile mechanism in striated muscle fibres. J. Physiol., 194: 51-74.

MASCher, D. and PePer, K. (1969) Two components of inward current in myocardial muscle fibers. Pflügers Arch., 307: 190-203.

NAYLER, W. (1963) Effect of caffeine on cardiac contractile activity and radiocalcium movement. Am. J. Physiol., 204: 969-974.

Niedergerke, R. (1963) Movements of $\mathrm{Ca}$ in frog heart ventricles at rest and during contractures. J. Physiol., 167: 515-550.

OCHI, R. and Trautwein, W. (1971) The dependence of cardiac contraction on depolarization and slow inward current. Pflügers Arch., 323: 187-203.

Reuter, H. and BeEler, R. W., Jr. (1969) Calcium current and activation of contraction in ventricular myocardial fibers. Science, 163: 399-401.

Reuter, H. and Seitz, H. (1968) The dependence of calcium efflux from cardiac muscle on temperature and external ion composition. J. Physiol. 195: 451-470.

Ritchie, J. M. (1954) The effect of nitrate on the active state of muscle. J. Physiol., 126: 155168.

Rougier, O., Vassort, G., Garnier, D., Gargouil, Y. M. and Coraboeuf, E. (1969) Existence and role of a slow inward current during the frog atrial action potential. Pflügers Arch., 308: $91-110$.

Rougier, O., VASSORT, G. and StäMPfLI, R. (1968) Voltage clamp experiments on frog atrial heart muscle fibers with the sucrose gap technique. Pflügers Arch., 301: 91-108.

SANDow, A. (1965) Excitation-contraction coupling in skeletal muscle. Pharmacol. Rev., 17: 265-320.

Sandow, A., Taylor, S. R., IsaAcson, A. and Seguin, J. J. (1964) Electrochemical coupling in potentiation of muscular contraction. Science, 143: 577-579.

SAndow, A., TAYlor, S. R. and Preiser, H. (1965) Role of the action potential in excitationcontraction coupling. Fed. Proc., 24: 1116-1123.

SuzUKI, K. (1962) Studies on the mechanism of the excitation-contraction coupling in cardiac muscle, with special reference to the caffeine-contracture. Jap. J. Physiol., 12: 186-199.

TANIGUCHI, M. and NAGAI, T. (1970) Effect of temperature on caffeine-induced calcium release from isolated reticulum in frog skeletal muscle. Jap. J. Physiol., 20: 61-71.

Weber, A. and Herz, R. (1968) The relationship between caffeine contracture of intact muscle and the effect of caffeine on reticulum. J. Gen. Physiol., 52: 750-759.

Winegrad, S. and Shanes, A. M. (1962) Calcium flux and contractility in guinea pig atrium. J. Gen. Physiol., 45: 371-394.

Wood, E. H., Heppner, R. L. and WeIDMAnN, S. (1969) I. Inotropic effects of constant electric currents or current impulses applied during cardiac action potentials. II. Hypotheses: Calcium movements, excitation-contraction coupling and inotropic effects. Circ. Res., 24: 409-445. 